\title{
Smoking increases the risk of infectious diseases: A narrative review
}

\author{
Chen Jiang ${ }^{1}$, Qiong Chen ${ }^{2}$, Mingxuan Xie ${ }^{1}$
}

\begin{abstract}
Smoking is relevant to infectious diseases resulting in increased prevalence and mortality. In this article, we aim to provide an overview of the effects of smoking in various infections and to explain the potential mechanisms. We searched PubMed and other relevant databases for scientific studies that explored the relationship between smoking and infection. The mechanisms of susceptibility to infection in smokers may include alteration of the structural, functional and immunologic host defences. Smoking is one of the main risk factors for infections in the respiratory tract, digestive tract, reproductive tract, and other systems in humans, increasing the prevalence of HIV, tuberculosis, SARS-CoV, and the current SARS-CoV-2. Smoking cessation can reduce the risk of infection. Smoking increases the incidence of infections and aggravates the progress and prognosis of infectious diseases in a dose-dependent manner. Smoking cessation promotion and education are the most practical and economical preventive measures to reduce aggravation of disease infection owing to tobacco use.
\end{abstract}

\author{
AFFILIATION \\ 1 Department of Gerontology and \\ Respirology, Xiangya Hospital, \\ Central South University, Changsha, \\ China \\ 2 National Clinical Research Centre \\ for Geriatric Disorders, Department \\ of Geriatrics, Xiangya Hospital, \\ Central South University, Changsha, \\ China

\section{CORRESPONDENCE TO} \\ Mingxuan Xie. Department of \\ Gerontology and Respirology, \\ Department of Gerontology and \\ Respirology, Xiangya Hospital, \\ Central South University, No. 86 \\ Xiangya Road, Changsha, Hunan, \\ China.E-mail: xiemx2015@163.com \\ KEYWORDS \\ smoking, tobacco, infection, \\ respiratory tract \\ Received: 24 December 2019 \\ Revised: 4 June 2020 \\ Accepted: 9 June 2020
}

\section{INTRODUCTION}

Smoking is one of the most severe public health problems in the world. According to the WHO Global report on trends in prevalence of tobacco use 20002025 , smoking accounts for $9 \%$ of all deaths worldwide, and more than half of smokers die from smoking-related diseases $^{1}$. China is the largest producer and consumer of tobacco in the world. In 2018 , about $26.6 \%$ of adults (aged $\geq 15$ years; 308 million in total) were current smokers and $44.9 \%$ of adults ( 515 million) were exposed to secondhand smoke at home ${ }^{1}$. Exposure to cigarette smoke and secondhand smoke is very harmful to human health. There are over 7000 chemical components in tobacco smoke, of these, over 250 are toxic or carcinogenic, such as aldehydes, nitrides, and others that irritate the respiratory tract. Nicotine leads to tobacco addiction; benzpyrene, arsenic, cadmium and other components have carcinogenic effects and nitric oxide can reduce oxygen transport by erythrocytes. Smoking can damage nearly all organs of the human body and is one of the main risk factors for respiratory infection and infectious diseases in other systems, in a dose-dependent manner ${ }^{2,3}$. In this review, we discuss the mechanisms and influence of smoking on infections in various systems, including the respiratory system, digestive system, and genital system, among others, in order to provide evidence for the active promotion of smoking cessation.

\section{DEVELOPMENTS}

\section{Mechanisms of susceptibility}

The potential mechanisms of how cigarette smoke increases the risk of systemic infections are not completely understood. These may include alteration 
of the structural, functional and immunologic host defences ${ }^{2}$.

\section{Structural and functional changes}

Harmful substances in cigarette smoke can interfere with the structure and function of the respiratory tract, the oral environment and the digestive tract, facilitating invasion by pathogenic organisms and increasing susceptibility to infections.

\section{Smoking and the respiratory tract}

The respiratory epithelium constitutes the first line of defence against inhaled pollutants and pathogens. Cigarette smoke can directly damage the airway epithelial barrier, including ciliated cells, goblet cells, basal cells, and submucosal secretory glands ${ }^{4}$. Toxic substances in cigarette smoke, as well as nicotine containing electronic cigarettes (e-cigarettes), can impair the continuity of ciliary oscillation ${ }^{5}$, and lead to mucus hypersecretion ${ }^{6}$, delayed mucociliary clearance $^{7}$, which is conducive to the colonization by and the reproduction of pathogens ${ }^{8}$. Relevant to these abnormalities, cigarette smoke perturbs the metabolism of human airway basal stem/progenitor cells, and affects the replenishment of mucociliary eplithelium ${ }^{9}$. Cigarette smoke can also impair the integrity of the airway epithelium, mainly by disruption of intercellular contacts ${ }^{10}$. The use of cigarettes ${ }^{11}$ and e-cigarettes ${ }^{12}$ diminishes cough reflex sensitivity in humans ${ }^{13}$, preventing the elimination of pathogens. Fortunately, cough sensitivity can be gradually restored as early as 2 weeks after smoking cessation $^{14}$.

The above structure alteration and dysfunction may be explained by the following reasons. Genetic changes, such as loss of heterozygosity $(\mathrm{LOH})$ and microsatellite instability (MSI), can be found in the bronchial epithelium of current or former smokers ${ }^{15}$. Cigarette smoking causes persistent DNA damage and inefficient DNA repair of epithelial lung cells, resulting in somatic mutations, as a form of $\mathrm{LOH}$ and $\mathrm{MSI}^{16-18}$. The accumulation of mutation induces cell death and tissue destruction, leading to barrier impairment and structural changes like metaplasia, dysplasia and airway structural reform ${ }^{19,20}$. Persistent or inefficient autophagy may be detrimental to lung epithelial cells, promoting lung injury ${ }^{21}$. Exposure to cigarette smoke is confirmed as a main contributor to the induction of mitochondrial dysfunction and mitophagy impairment, along with the accumulation of damaged mitochondrial DNA ${ }^{22}$. Enhanced mitophagy can cause injury and senescence in airway epithelial cells, impairing the barrier integrity. Insufficient mitophagy may exaggerate airway wall thickening and emphysematous changes, contributing to structural changes and increased susceptibility to infection ${ }^{23-25}$. The reactive oxygen species (ROS) in cigarette smoke disturbs mitochondrial function in airway epithelial cells by decreasing the ability of mitochondria for ATP synthesis. Mitochondrial disfunction leads to cellular necrosis and progressive inflammation in the lungs, promoting tissue remodeling and susceptibility to infection $^{26-29}$. Nitric oxide is endogenously released in the airways by nitric oxide synthase, and can interact with ROS and oxygen free radicals to form other reactive nitrogen species (RNS) after inhalation of cigarette smoke, all of which are essential in the killing of invading microorganisms. In addition, smoking can decrease the activity of endothelial nitric oxide synthase ${ }^{30}$, leading to decreased lung protection function. Enhanced levels of ROS and RNS by cigarette smoking are able to compromise cell function by damaging DNA, lipids, proteins, and carbohydrates, inducing several pathophysiological conditions such as apoptosis and necrosis ${ }^{31,32}$. The large amounts of free radicals in cigarette smoke can damage the integrity of respiratory tract and alveolar epithelial cells, leading to an increased likelihood of infection.

\section{Oral environment}

Smoking is associated with excessive destruction of the supporting periodontal tissues, resulting in bone loss, pocket formation, and premature tooth $\operatorname{loss}^{33}$. Cigarette smoke extract at high concentrations inhibits osteoblast-like cell proliferation and differentiation. On the other hand, smoking carcinogen exposure may increase activity of existing osteoclasts. Both of these would contribute to increased bone resorption ${ }^{34,35}$. Kubota et al. ${ }^{36}$ found augmented alveolar bone loss, delayed alveolar bone recovery and increased number of osteoclasts in a mouse periodontitis model. Smoking changes the life span and apoptosis of periodontal ligament fibroblasts and inhibits the growth and adhesion of fibroblasts, making it difficult to restore damaged periodontal tissues. Smoking 
can influence the oral environment by inducing hypoxia, lowering the periodontal redox potential and affecting the subgingival micro-environment, which is beneficial to the survival of anaerobic bacteria ${ }^{37}$. Smoking may alter the transcription and methylation status of extracellular matrix-related genes, which may exacerbate periodontitis ${ }^{38}$.

\section{The digestive tract}

Cigarette smoke and its active compounds impair the fundamental structure of the gastrointestinal tract through the induction of cellular apoptosis and the inhibition of mucosal cell renewal ${ }^{39}$. A number of studies have shown that cigarette smoke can induce cell apoptosis in the esophagus and gastric mucosa, as well as in the inner layers of the small intestine and colon, impairing integrity of the mucous. Smoking can be associated with increased risk for gastrointestinal metaplasia, chronic gastric mucous atrophy, and gastric cancer-like dysplasia ${ }^{40-42}$. Cigarette smoke also interferes with the protective function of the gastrointestinal tract by the contraction and spasm of the gastric submucosal blood vessels, leading to mucosal ischemia and hypoxia. A decrease in gastric mucosal blood flow is an important factor in destruction of the integrity of the gastric mucosa ${ }^{43}$. Smoking can cause disorders of the pyloric sphincter function and hinder the reflux of intestinal fluid. Smoking can also affect prostaglandin synthesis in the duodenal mucosa of the stomach, reducing mucus volume and mucosal blood flow, thereby impairing the defence function of the mucosa and making the gastric mucosa more susceptible to infection. Smoking may affect the closing function of the pyloric sphincter, which can lead to bile reflux and damage to the gastric mucosal barrier. Accumulated bile will stimulate the gastric mucosa to increase gastric acid secretion, causing contraction of blood vessels in the stomach wall and increasing the chance of infection with H. pylori (HP).

\section{Immunity}

The impact of smoking on immunity is complex, with both pro-inflammatory and immunosuppressive effects $^{44}$. Long-term and high-dose exposure of cigarette smoking can significantly damage the immune system and cause an imbalance in the inflammatory response ${ }^{45}$. Under the influence of cigarette smoke, both innate immunity and adaptive immunity can be observed with cell dysfunction and reduced effector molecules ${ }^{46,47}$, eventually leading to the colonization of the pathogen and the occurrence of infections.

\section{Smoking and innate immunity}

The most important part of innate immunity are innate immune cells, including macrophages, epithelial cells, dendritic cells and natural killer cells etc. A shorttime tobacco smoke exposure can generally stimulate immunity, activating and increasing macrophages and neutrophils with increased inflammatory mediators [tumor necrosis factor (TNF-a), interleukin (IL)$1 \beta$, IL- 8 , and leukotriene B $]^{45}$. Long-term chronic inflammation and cigarette smoke exposure, can damage innate immune cells and inhibit the production of immune molecules, leading to the rapid spread and long-term colonization of pathogens ${ }^{45,46}$. Cigarette smoking suppresses the phagocytosis of bacteria and apoptotic cells in macrophages ${ }^{48-51}$. Cigarette smoking is also associated with a decreased number, inhibited maturation, and reduced expression, of IFN-a in dendritic cells ${ }^{52-54}$. Moreover, cigarette smoking can reduce cytotoxicity and cytoactivity of natural killer cells, decreasing the expression of IFN- $\gamma$ and TNF-a in natural killer cells ${ }^{55,56}$. Corriden et al. ${ }^{57}$ revealed that e-cigarette inhalation can reduce human neutrophil chemotaxis, phagocytosis, and neutrophil extracellular trap formation. All of these cells and molecules are important in the host defence against infection, thereby smoking increases the risk, severity and duration of infection.

Smoking can also lower the level of some antibacterial molecules. Moore et al. ${ }^{58}$ suggested that cigarette exposure impairs a multifunctional innate defence protein named 'Short palate lung and nasal epithelial clone 1 (SPLUNC1)', which is secreted into airway surface liquid by the underlying epithelia and also is a key component of the innate immune response to infections, especially gram-negative organisms. Duffney et al. ${ }^{59}$ found that cigarette smoke exposure impairs antiviral responses in lung epithelial cells by decreasing the phosphorylation of the key antiviral transcription factor, interferon response factor 3 . In addition, cigarette smoke can suppress immune activation and the expression and secretion of effector cytokines in peripheral blood mononuclear 
cells, resulting in a reduced immune response ${ }^{60}$.

\section{Smoking and adaptive immunity}

Smoking damages adaptive immune cells and reduces the release of effector molecules. Warny et al. ${ }^{61}$ found that smoking status is a risk factor for lymphopenia. Bhat et al. ${ }^{62}$ proved that chronic secondhand smoking impairs B- and T-cell responses and reduces the production of antibodies in both serum and bronchoalveolar lavage samples. Patin et al. ${ }^{63}$ observed that active smoking significantly increased the number of circulating immune cells: circulating CD $45+$ cells by $23 \%$ (99\% CI: $11-37 \%$ ), and conventional lymphocytes by $26 \%$ (99\% CI: $10-$ $45 \%)$. Cigarettes can reduce human immunoglobulin levels in serum and saliva. Gonzalez et al. ${ }^{64}$ and Nesrin et al. ${ }^{65}$ found decreased IgG levels in smokers. Maria et al. ${ }^{66}$ reported lower levels of salivary $\operatorname{IgA}, \operatorname{IgG}$, and IgM in smokers than in non-smokers. Serum IgG and IgM levels will rise significantly after smoking cessation ${ }^{67}$. Cigarette smoke inhibits expression and secretion of effector cytokines, such as IFN $\gamma$, TNF and IL-2 proteins, resulting in a reduced immune response $\mathrm{e}^{60,68}$.

\section{Smoking and respiratory infections}

Many large national and international studies state that there is sufficient evidence that smoking is closely related to various respiratory infections, with a clear dose-response, including acute respiratory tract infection (ARTI) and particularly communityacquired pneumonia (CAP). The pathogens involved in these findings include bacteria, fungi, viruses, and Mycobacterium tuberculosis. Smoking cessation can reduce the risk of morbidity.

\section{Smoking and CAP}

CAP is a common respiratory infection, and pathogens related to CAP include Streptococcus pneumoniae, Mycoplasma pneumoniae, Chlamydia pneumoniae, and several respiratory viruses, among others. Smoking can substantially increase the morbidity and mortality risk of CAP whereas smoking cessation can reduce the risk of morbidity. Baik et al. ${ }^{69}$ reported that the risk of CAP in smokers is approximately 1.5 times that of non-smokers (95\% CI: 1. 00-2.14), regardless of sex. For male smokers, who smoke more than 25 cigarettes per day, the rate of CAP can increase 2.54 times (95\%
CI: 1.40-4.59) that of non-smokers. Almirall et al. ${ }^{70}$ proved that for those who smoked more than 20 cigarettes daily, the risk was increased by 3.89 (95\% CI: $1.75-8.64)^{70}$. As for older people, the risk of CAP in smokers is 2.3-3.1 times that of non-smokers ${ }^{71,72}$. Nuorti et al. ${ }^{73}$ confirmed that smoking is the strongest independent risk factor for invasive pneumococcal disease, and the morbidity of CAP in smokers is 4.1 times that of non-smokers (95\% CI: 2.4-7.3). In addition, the CAP risk of passive smokers is 2.5 times that of non-smokers (95\% CI: 1.2-5.1). Smoking cessation can reduce the risk of CAP. Compared with individuals who quit smoking for less than 1 year, the risk of CAP has been found to be significantly lower among individuals who had quit smoking for more than 4 years $(\mathrm{OR}=0.39 \text {; 95\% CI: } 0.17-0.89)^{74}$. After 5 years of smoking cessation, the risk of CAP in former smokers is nearly the same as that of non-smokers ${ }^{75}$.

\section{Smoking and acute respiratory tract infection (ARTI)}

Generally speaking, ARTI is caused by viruses (70$80 \%$ ), including rhinovirus, coronavirus, adenovirus, influenza and parainfluenza virus, and respiratory syncytial virus. Another $20-30 \%$ of ARTIs can be attributed to bacteria. There is sufficient evidence that smoking increases the risk and recurrence rate of upper respiratory tract infections, whereas smoking cessation can reduce these. Cohen et al. ${ }^{76}$ showed that the risk of developing a clinical cold in smokers was 2.08 times that of non-smokers (95\% CI: 1.18-3.70). Blake et al. ${ }^{77}$ found that the risk of ARTI among nonsmokers (95\% CI: 1.1-1.8) is 1.46 times lower than that of smokers. An et al. ${ }^{78}$ discovered that in those who smoked on $1-4,5-10,11-20$, or 21-30 days during the previous 30 days, the prevalence of one or more days of cough or sore throat increased by $5.8 \%, 9.5 \%, 8.9 \%$, and $11.0 \%$, respectively. Aronson et al. ${ }^{79}$ revealed that smokers are more prone to ARTI, with a longer cough duration ( 8.9 vs 6.8 days) and an increased risk of lower respiratory illnesses ( $57 \%$ vs $45 \%$ ). Zhou et al. ${ }^{80}$ reported that passive smokers are 1.59 times more likely to have a cold than non-smokers (95\% CI: $1.27-1.99)$. Guan et al. ${ }^{81}$ revealed that smoking habits among family members is an independent risk factor for recurrent ARTI in children. Smoking in the mother can cause fetal respiratory movement fatigue in the uterus, impair 
fetal respiratory function, and reduced respiratory defence function.

Smoking can weaken the potency of influenza vaccines, reducing their protective effect and thereby increasing the morbidity of influenza and hospitalization. Godoy et al. ${ }^{82}$ discovered that hospitalization among smokers was 1.32 times that of non-smokers (95\% CI: 1.04-1.68). Influenza virus subunit vaccines can help to protect smokers from hospitalization at a rate of $21 \%$ (95\% CI: $-2,39 \%)$ whereas non-smokers have a protection rate of $39 \%$ (95\% CI: $22-52 \%$ ). Park revealed that there is a low rate of vaccination among ex-smokers $(\mathrm{OR}=0.734$; 95\% CI: 0.63-0.854). In addition, smokers have an increased influenza viral load after infection, which aggravates tissue lesions ${ }^{83}$. Lee et al. ${ }^{84}$ found that mice exposed to cigarette smoke had faster virus proliferation and higher viral load.

\section{Smoking and COVID-19}

The current COVD-19 pandemic, which is caused by severe acute respiratory syndrome coronavirus 2 (SARS-CoV-2), has caused more than 370000 deaths ${ }^{85}$. The relationship between smoking and COVID-19 is controversial ${ }^{86}$. Many studies show that smoking increases the incidence and severity of COVID-19. Smoking upregulates angiotensinconverting enzyme 2 (ACE2), the receptor of SARSCoV-2 and SASR-CoV, increasing susceptibility to COVID-19 and Severe Acute Respiratory Syndrome (SARS) infection ${ }^{87-91}$. High expression of ACE2 is also related with cytokine storm and immune system dysfunction, leading to lung injury in both COVID-19 and SARS patients ${ }^{92,93}$. A community-based cohort study of 387109 adults in the UK illustrated that smoking increases the risk of COVID-19 $(\mathrm{RR}=1.42$; 95\% CI: $1.12-1.79)^{94}$. Vardavas and Nikitara ${ }^{95}$ found that smokers were more likely to have more severe symptoms of COVID-19 ( $\mathrm{RR}=1.4$; 95\% CI: $0.98-$ 2.00) and were more likely to be admitted to the intensive care unit, require mechanical ventilation or die, in comparison with non-smokers $(\mathrm{RR}=2.4$; 95\% CI: $1.43-4.04)$. Liu et al. ${ }^{96}$ concluded that a history of smoking can lead to the progression of COVID-19 pneumonia (OR=14.285; 95\% CI: 1.577 25.000). Guan et al. ${ }^{97}$ analyzed the smoking status in 1099 COVID-19 patients, finding that smoking rate in patients with poor outcomes is higher than that without poor outcomes (25.8\% vs $11.8 \%)$. In addition, males, with high rates of smoking, tend to have more serious complications in SARS and Middle East Respiratory Syndrome (MERS) ${ }^{98-101}$. This sex predisposition can be observed in COVID-19, which indirectly suggests the relationship between smoking and COVID-19 ${ }^{102}$.

However, there are different views. The prevalence of smoking among people with COVID-19 was about 5.4\% (95\% CI: $3.5-7.7 \%)^{103}$, and such a low prevalence may not support that smoking increases the risk of SARS-CoV-2 infection. Simon et al. ${ }^{104}$ found that active smoking was associated with lower odds of having a positive test result, which may be explained by selection bias and affected nasopharyngeal viral load by smoking. A meta-analysis by Lippi ${ }^{105}$ showed no significant association between active smoking and severity of COVID-19 (OR=1.69; 95\% CI: 0.41-6.92; $\mathrm{p}=0.254)$. But Guo ${ }^{106}$ corrected the meta-analysis of Lippi and found that the pooled OR was 2.20 (95\% CI: $1.31-3.67 ; \mathrm{p}=0.003$ ) and the latest meta-analysis by Roengrudee $^{107}$ shows that smoking is a risk of disease progression in COVID-19 (OR=1.91; 95\% CI 1.422.59). In conclusion, currently limited epidemiological evidence are insufficient to draw a firm conclusion, but a warning for smoking cessation in the pandemic of COVID-19 is necessary ${ }^{102,108,109}$.

\section{Smoking and infection with different respiratory pathogens}

Smoking increases the risk of influenza infection and hospitalization. Kark et al. ${ }^{110}$ found that smokers are 1.44 times more likely to have influenza infection than non-smokers (95\% CI: 1.03-2.01; incidence rate $60.0 \%$ vs $41.6 \%$ ). Kark et al. ${ }^{111}$ also demonstrated that smokers are 2.49 times more likely to contract influenza than non-smokers (95\% CI: 1.56-3.96; incidence rates $68.5 \%$ vs $47.2 \%$ ). Mustafa et al. ${ }^{112}$ revealed that the risk of death for active smokers with influenza is 7.08 times greater than that of other groups. A multicenter case-control study of 2554 people aged $>65$ years in Spain showed that smoking is associated with an increased risk of hospitalization for influenza (OR=1.32; 95\% CI: 1.04-1.68). The effectiveness of influenza vaccination for non-smokers is higher than that of smokers ( $39 \%$ vs $21 \%)^{82}$. Heavy smoking history ( $\geq 20$ pack-years) is an independent risk factor for influenza occurrence in hospitalized 
patients with chronic obstructive pulmonary disease (COPD) $(\mathrm{OR}=3.056$; 95\% CI: 1.072-8.715; $\mathrm{p}=0.037)^{113}$.

Smoking can increase the morbidity of pneumococcal disease. Research by Flory et al. ${ }^{114}$ showed that the incidence of streptococcus pneumonia in non-smokers is 5.1/100000 (95\% CI: 4.2-6.2), and the incidence in smokers is significantly higher at 16.3/100000 (95\% CI: 14.6-18.1), the risk ratio of smoking is 2.2 (95\% CI: 1.7-3.0), and the attributable risk is $35.6 \%$. A study in Australia also found that smokers are 3.7 times more likely to develop Streptococcus pneumonia than non-smokers ${ }^{115}$.

Smokers are more likely to develop Legionella pneumonia than non-smokers. Straus et al. ${ }^{116}$ confirmed that the risk of Legionella pneumonia among smokers is 3.75 times that of non-smokers (95\% CI: 2.27-6.17). The greater the daily smoking amount the higher the risk of Legionella pneumonia. Research by Doebbeling et al. ${ }^{117}$ also showed that smoking is an independent risk factor of Legionella pneumonia.

The risk of pulmonary fungal disease, such as coccidioidomycosis, cryptococcosis etc., is considerably increased in smokers. In Italy, a study conducted in 33 medical centers revealed that smoking can increase the risk of cryptococcosis among people with and without HIV ${ }^{118}$. Rosenstein et al. ${ }^{119}$ found that smoking in the previous 6 months is an independent risk factor of severe coccidioidomycosis, with a ratio of 2.4 (95\% CI: 1.1-5.4).

Smoking exposure during pregnancy may cause disease by altering RSV and changing neonatal immune responses, which can increase the risk of respiratory tract infection. Cheemarla et al. ${ }^{120}$ showed that intrauterine smoke exposure in a mouse model led to increased lung inflammation, with increased neutrophil influx into the airway of infected mice and delayed virus clearing; however, the authors found that RSV-specific CD8 ${ }^{+} \mathrm{T}$ cells had a decreased response.

\section{Smoking and tuberculosis infection}

Both active and passive smoking can increase the risk of tuberculosis. The World Health Organization 2007 Global Tuberculosis Report clearly pointed out that smoking is one of the five major risk factors for tuberculosis infection. In 830000 patients newly diagnosed with tuberculosis, the increased risk of contracting the disease is attributed to smoking. The morbidity of tuberculosis in smokers is 1.6-2.5 times that of non-smokers ${ }^{121}$; a similar conclusion has been reached in several large meta-analyse ${ }^{122-124}$. Lin et al. ${ }^{125}$ demonstrated that smokers were 1.94 times more likely to have active tuberculosis than nonsmokers (95\% CI: 1.01-3.73). Oztürk et al. ${ }^{126}$ proved that tobacco abuse (over 20 packs/year) and smoking from a young age ( $<16$ years) is the key factor of active tuberculosis. David et al. ${ }^{127}$ found that the incidence of latent tuberculosis infection (LTBI) in non-smokers, previous smokers, and current smokers is $4.1 \%, 6.2 \%$, and $6.6 \%$, respectively; the risk of LTBI among non-smokers (95\% CI: 1.1-2.9) was 1.8 times lower than that of current smokers. Bronner et al. ${ }^{128}$ conducted a case-control study in 146 patients from South Africa with tuberculosis and HIV coinfection. The authors discovered that the median CD4 cell count of the smoking group was lower $\left(60 / \mathrm{mm}^{3} \mathrm{vs}\right.$ $\left.81 / \mathrm{mm}^{3}\right)$ and the median viral load higher $(173 / \mu \mathrm{L}$ vs $67 / \mu \mathrm{L}$ ) among current and past smokers with HIV, and the risk of tuberculosis in these individuals was 3.2 times (95\% CI: $1.3-7.9$ ) and 1.8 times (95\% CI: 0.8-4.4) that of non-smokers with HIV.

There is evidence that smoking can adversely affect the therapeutic efficacy and prognosis of tuberculosis. Leung et al. ${ }^{129}$ found that current smokers with a history of tuberculosis have a significantly higher risk of tuberculosis recurrence than non-smokers $(\mathrm{OR}=2.48$; 95\% CI: $1.04-5.89)$. Abal et al. ${ }^{130}$ revealed that the duration of sputum negative conversion among smokers with tuberculosis is significantly prolonged. Tan et al. ${ }^{131}$ revealed that, with the same treatment, the sputum negative conversion rate among smokers is significantly lower than that of non-smokers. Chuang et al. ${ }^{132}$ confirmed that smokers have a higher rate of failure in tuberculosis treatment $(33 \%)$ and a more serious $\mathrm{x}$-ray classification of lung lesions. Smokers require a longer treatment period to convert the sputum culture from positive to negative ( $\mathrm{HR}=1.12$; 95\% CI: 1.03-1.39). Xiong et al. ${ }^{133}$ reported that the lesion absorption rate in their non-smoking group (85.7\%) was significantly higher than in the smoking group (54.5\%). One possible reason for this is that smokers have lower serum albumin levels, which results in a lack of protein to supply lesion repair during treatment 
and slows sputum negative conversion. A significant increase in the mortality rate among smokers with tuberculosis has been reported. A prospective cohort study of 486341 adults in Taiwan showed that the tuberculosis mortality rate among smokers is 9 times that of non-smokers ${ }^{134}$. In India, Gajalakshmi et al. ${ }^{135}$ found that people with a history of smoking are 4.5 times more likely to die from tuberculosis than nonsmokers $(\mathrm{RR}=4.5$; 95\% CI: 4.0-5.0; the attribution rate of smoking is $61 \%$ ).

\section{Smoking and digestive system infections Smoking and Helicobacter pylori (HP) infections}

HP infection is an important risk factor for digestive diseases such as peptic ulcer, chronic gastritis, and gastric cancer. Smoking is an independent risk factor for HP infection, which can increase the morbidity of HP infection and lead to a poor radical treatment. In a study from China, the HP infection rate in the smoking group $(51.01 \%)$ was significantly higher than that in the non-smoking group $(38.27 \%)^{136}$. Another study also showed that the HP infection rate among smokers was significantly higher than that of non-smokers, and smoking is an independent risk factor for HP infection ${ }^{137}$. Chen et al. ${ }^{138}$ revealed that smoking can cause failure of anti-HP treatment. Itskoviz et al. ${ }^{139}$ demonstrated that the failure of HP radical treatment is positively correlated with current smoking (OR=1.15; 95\% CI: 1.10-1.20).

\section{Smoking and Clostridium difficile infections (CDI)}

Clinically, CDI can cause mild diarrhea to bloody diarrhea, which can lead to pseudomembranous colitis, toxic megacolon, intestinal necrosis, and can even be life-threatening. Smoking increases the risk of CDI and is associated with poor prognosis. Rogers et al. ${ }^{140}$ discovered that the risk of CDI among former smokers was increased by $33 \%$ in comparison with non-smokers, whereas in current smokers, the risk of CDI was increased by $80 \%$. Barker et al. ${ }^{141}$ found that infection in patients with a history of smoking was significantly less likely to be cured within 2 weeks than in non-smokers. Ruiter et al. ${ }^{142}$ conducted a retrospective cohort study in a national sample of pregnant women and showed that smoking increased the diagnostic rate of CDI in pregnant women who were hospitalized (adjusted OR, AOR $=1.4 ; 95 \%$ CI: 1.2-1.7). Garg et al. ${ }^{143}$ revealed that smoking increases the chance of emergency CDI hospitalization.

\section{Smoking and anal abscess}

Studies have shown that smoking increases the risk of anal abscesses. Zheng et al. ${ }^{144}$ reported that smoking is associated with anal abscess and anal fistula disease (OR=12.331; 95\% CI: 8.364-18.179). Devaraj et al. ${ }^{145}$ proved that the risk of anal abscess/anal fistula among military veterans with a smoking history within 1,5 and 10 years was $2.15,1.72$, and 1.34 times that of non-smoking veterans, respectively. These findings suggest that a recent smoking history (within 1 year) is a significant risk factor for anal abscess/anal fistula $(\mathrm{OR}=2.15 ; 95 \%$ CI: $1.34-3.48)$. Wang et al. ${ }^{146}$ also discovered that smoking is an independent risk factor for anal fistula ( $\mathrm{OR}=4.300 ; 95 \%$ CI: 3.640-5.080).

\section{Smoking and genital tract infection Smoking and human papillomavirus (HPV) infection}

The main types of HPV are HPV 1, 2, 6, 11, 16, 18, 31, 33 and 35; cervical cancer may be related to long-term infection of HPV16 and 18. Smoking can increase the morbidity of HPV infection in both man and women. A multicenter randomized controlled trial ${ }^{147}$ conducted among women in the United States showed that smoking increases the risk of HPV infection by lowering the immune response. Current smokers have a higher risk of infection with HPV16 $(\mathrm{OR}=1.29$; 95\% CI: 1.11-1.73) than non-smokers. Women who smoke more than 10 cigarettes per day $(\mathrm{OR}=1.59$; 95\% CI: $1.27-2.15)$ are at higher risk than those who smoke less than 10 per day $(\mathrm{OR}=1.09 ; 95 \% \mathrm{CI}$ : 0.94-1.44). Feng et al. ${ }^{148}$ found that passive smoking does not cause a continually increased risk of HPV infection (OR=1.11;95\% CI: 1.00-1.24). In men, Liu et al. ${ }^{149}$ demonstrated that smoking can result in $\mathrm{HPV}$ infection (adjusted prevalence ratio, $\mathrm{APR}=3.58$; 95\% CI: 1.81-7.08) and can lead to high-risk HPV infection (APR=4.08; 95\% CI: 1.52-10.94). Another study on the prevalence of oral HPV in patients with special healthcare needs found that both current and former smokers have a higher risk of developing oral HPV infection, and smokers have higher HPV viral loads than non-smokers ${ }^{150}$.

\section{Smoking and Trichomonas vaginalis (TV) infection}

Infection with TV is the most common curable 
sexually transmitted infection (STI) in the world and can increase the risk of pelvic inflammatory disease (PID), HIV transmission and premature delivery. In Brazil, a survey on the risk factors for TV infection showed that smoking increases the risk of infection with TV (AOR=1.66; 95\% CI: 1.04-2.64 $)^{151}$. In Kenya, a 2-year longitudinal study of STIs among 350 female sex workers found that smoking history is a risk factor for increased incidence of TV within 2 years $(\mathrm{HR}=2.66 ; 95 \% \text { CI: } 1.24-5.73)^{152}$.

\section{Smoking and mycoplasma and chlamydia infection in the genital tract}

Mycoplasma genitalium and Chlamydia trachomatis (CT) infections are associated with female genital diseases, including cervicitis, urethritis, PID, infertility, ectopic pregnancy, adverse delivery outcomes, and HIV infection. Balkus et al. ${ }^{153}$ proved that smoking is independently associated with an increased risk of genital mycoplasma infection $(\mathrm{AHR}=3.02 ; 95 \% \mathrm{CI}$ : 1.32-6.93). Adamma et al. ${ }^{154}$ conducted a cohort study among 954 young women; the results showed that smoking increases the incidence of genital chlamydia infection ( $\mathrm{RR}=2.2$; 95\% CI: $1.2-3.9)$.

\section{Smoking and other infections Skin infections}

A retrospective cohort study showed that smoking during pregnancy can increase the incidence of skin infections in those aged $<17$ years $(\mathrm{HR}=1.21$; $95 \%$ CI: 1.13-1.30), especially for children under 1 year of age. Smoke-free pregnancy can reduce the rate of hospitalization for skin infections in children by $9.6 \%$. Smoking during pregnancy may lower the child's immunity and increase the risk of infection ${ }^{155}$.

\section{Otitis media}

Both active and passive smoking can cause acute otitis media, recurrent otitis media, and middle ear effusion in children. In 2006, the U.S. Surgeon General's Report pointed out that children whose parents smoked were 1.0-1.5 times more likely to have acute otitis media than those whose parents did not smoke. The rate of recurrent otitis media in children whose parents smoked was 1.37 times higher than that of children whose parents did not smoke (95\% CI: 1.10-1.70). In 2013, a cohort follow-up study in 400 mother-child pairs showed that smoking habits of mother (current habit and former habits; $\mathrm{HR}=2.00$; 95\% CI: 1.19-3.36) can cause otitis media in children aged $<4$ years $(\mathrm{HR}=1.17 \text {; 95\% CI: } 1.05-1.31)^{156}$. Studies have shown that exposure to cigarette smoke among exposure of pregnant women is associated with an increased risk of otitis media in infants. A study of 72 patients with an acute ear infection showed that the risk of acute ear infection in infants is closely related to the daily smoking amount of mother during pregnancy, as follows: $1-9$ cigarettes $(\mathrm{OR}=1.6$; 95\% CI: $1.1-2.5), 10-19$ cigarettes ( $\mathrm{OR}=2.6$; $95 \% \mathrm{CI}$ : 1.6-4.2), more than 20 cigarettes $(\mathrm{OR}=3.3$; 95\% CI: 1.9-5.9). The risk of subacute ear infection in infants is also closely related to the mother's daily smoking amount: $10-19$ cigarettes (OR=2.6; 95\% CI: 1.4-5.0), and $>20$ cigarettes $(\mathrm{OR}=2.8 ; 95 \% \text { CI: } 1.3-6.0)^{157}$.

\section{Periodontal infections}

Smoking can cause an increased rate of periodontal infection. Ojima et al. ${ }^{158}$ studied the data from two national adult sample surveys (dental disease survey and national nutrition survey) in Japan. They found that the prevalence of periodontitis and other severe periodontal infection in non-smokers, former smokers, and current smokers was $39.3 \%$ and $49.5 \%, 47.3 \%$ and $7.9 \%, 11.7 \%$ and $12.4 \%$, respectively. Among people aged $>40$ years, the risk in current smokers of general periodontitis and more severe periodontal infection was 1.38 times (95\% CI: $1.12-1.71$ ) and 1.40 times (95\% CI: 1.04-1.89) that of non-smokers, respectively. Tomar et al. ${ }^{159}$ reported that the rate of periodontitis among current smokers is 3.97 times that of non-smokers (95\% CI: 3.20-4.93); as for previous smokers, the rate is 1.68 times that of non-smokers (95\% CI: 1.31-2.17). Another study showed that the risk of periodontitis in those who smoke fewer than $9,10-19,20,21-31$ and $>31$ cigarettes per day was 2.79 times (95\% CI: 1.90-4.10), 2.96 times (95\% CI: $2.12-4.14$ ), 4.72 times (95\% CI: 3.46-6.43), 5.10 times (95\% CI: 3.48-7.47) and 5.88 times (95\% CI: 4.03-8.58) that of non-smokers, respectively. The risk of periodontitis in patients who have quit smoking for $<2,3-5,6-10$, and $>11$ years is 3.22 times $(95 \%$ CI: 2.18-4.76), 2.27 times (95\% CI: 1.26-4.07), 1.99 times (95\% CI: 1.23-3.21) and 1.15 times (95\% CI: 0.83-1.60) that of non-smokers, respectively.

Smoking can lead to severe periodontitis and increased periodontal injury. Zhang et al. ${ }^{160}$ 
demonstrated that smoking is an independent risk factor for the onset of severe periodontitis in the elderly, and the morbidity of severe periodontitis in smokers is 3.160 times that of non-smokers (95\% CI: $1.051-1.310)$. Kinane et al. ${ }^{161}$ confirmed that smokers have decreased periodontal pocket depth and adhesion levels than non-smokers after non-surgical or surgical treatment. Zhao et al. ${ }^{162}$ proved that the proportion of periodontitis is increased in smokers, and the greater the degree of smoking, the deeper the periodontal pockets and the greater the attachment loss.

\section{Bacteremia}

Studies have shown that the incidence of bacteremia in smokers is significantly increased, which is an important risk factor for poor prognosis and mortality of bacteremia ${ }^{163}$. In a retrospective analysis of the clinical data of 67 patients in a Spanish hospital with positive blood cultures for Streptococcus pneumoniae from January 1999 to October 2010, investigators found that smoking was the main risk factor for pneumococcal bacteremia ${ }^{164}$.

\section{HIV Infection}

Studies have shown that smokers have a higher rate of HIV infection and morbidity of AIDS. Mdodo et al. ${ }^{165}$ reported that in patients with HIV, 42.4\% (95\% CI: $39.7-45.1 \%)$ were current cigarette smokers, $20.3 \%$ (95\% CI: $18.6-22.1 \%$ ) were former smokers, and $37.3 \%$ (95\% CI: 34.9-39.6\%) had never smoked. A 7.9-year longitudinal study in 924 women with low socioeconomic status found that smokers have a higher risk of developing AIDS ( $\mathrm{HR}=1.36$; 95\% CI: $1.07-1.72$ ) and a higher mortality rate. Smokers display weak viral immune responses and are more likely to have failure of immunotherapy ${ }^{166}$.

There are also increased opportunistic infections and a decreased treatment efficacy among HIVinfected smokers ${ }^{167}$. Clinical consequences of the cumulative effects of HIV infection and smoking may increase the risk of pneumonia, COPD, cardiovascular disease and non-AIDS cancer among smokers ${ }^{168-174}$. Cigarette smoking may have a cumulative immunosuppressive effect in HIV patients. Compared with HIV-infected non-smokers, a marked depression in lung $\mathrm{CD}^{+}$and $\mathrm{CD}^{+}$lymphocytes and suppressed spontaneous production of the proinflammatory cytokines IL- $1 \beta$ and TNF- $\alpha$ can be observed in HIVinfected smokers ${ }^{167,175}$. Smoking in HIV infected people can lead to impaired function of $\mathrm{CD}^{+}$and $\mathrm{CD}^{+} \mathrm{T}$ cells and increased intestinal bacterial translocation ${ }^{176}$. These may explain why smoking can lead to increased opportunistic infections like oral candidiasis, esophageal candidiasis and pneumocystis pneumonia in HIV-positive patients ${ }^{177}$. In addition, cigarette smoking is associated with decreased efficacy of treatment, resulting in reduced immunological reaction ${ }^{167}$.

\section{Smoking and surgical site infection (SSI)}

Smoking increases the incidence of SSI. Forsythe et al. ${ }^{178}$ stated that smoking status $(\mathrm{OR}=1.7 ; 95 \%$ CI: 1.4-1.9) is an independent risk factor for SSI development. Baier et al. ${ }^{179}$ also revealed that smoking was an independent risk factor for postoperative SSI $(\mathrm{OR}=2.22$; 95\% CI: 1.27-3.90). One study showed that after surgery for adult spinal deformity and distal femoral fractures, the wound infection risk in the smoking group was higher than that of the non-smoking group ${ }^{180,181}$. For patients with diabetes, smoking is a risk factor of postoperative infection. Peng et al. ${ }^{182}$ proved that smoking is a risk factor for wound infection after lumbar surgery in patients with diabetes ( $\mathrm{OR}=3.830$; 95\% CI: $1.003-6.684)$; however, 4 weeks of strict smoking cessation prior to surgery reduced the risk of wound infection. Smoking results in an increased risk of infection at other sites after surgery with a prolonged hospitalization time and increased expenses. In patients after total hip arthroplasty (THA), Debbi et al. ${ }^{183}$ found that the hospitalization time and the total hospitalization costs were significantly increased in smokers. Matharu et al. ${ }^{184}$ discovered that compared with non-smokers and former smokers, current smokers have an increased risk of lower respiratory tract infection after primary THA and total knee arthroplasty. Additionally, a retrospective study of 206 transsexual men who underwent testicular implantation between January 1992 and December 2018 found that smoking history was a risk factor for postoperative infection and prosthetic transplantation $^{185}$.

\section{CONCLUSION}

Smoking can substantially increase the incidence and the mortality of infections in a clear dose- 
dependent manner. In addition, smoking leads to a poor prognosis. The recurrence rate and uncured rate of infection in smokers are higher than in nonsmokers. Smoking cessation can reduce damage owing to smoking and reduce the risk of infection. Active smoking cessation promotion and education are practical and cost-effective measures to prevent the risk of infection caused by smoking and to reduce the incidence rate and mortality of infection. Encouraging smokers to be vaccinated is also important to avoid infection.

\section{REFERENCES}

1. Chinese Center for Disease Control and Prevention. [2018 Adult Tobacco Survey Report]. http://www.chinacdc.cn/ jkzt/sthd_3844/slhd_4156/201908/t20190814_204616. html. Published 2019. Accessed December 24, 2019.

2. Arcavi L, Benowitz NL. Cigarette smoking and infection. Arch Intern Med. 2004;164(20):2206-2216. doi:10.1001/archinte.164.20.2206

3. Huttunen R, Heikkinen T, Syrjanen J. Smoking and the outcome of infection. J Intern Med. 2011;269(3):258269. doi:10.1111/j.1365-2796.2010.02332.x

4. Aghapour M, Raee P, Moghaddam SJ, Hiemstra PS, Heijink IH. Airway Epithelial Barrier Dysfunction in Chronic Obstructive Pulmonary Disease: Role of Cigarette Smoke Exposure. Am J Respir Cell Mol Biol. 2018;58(2):157-169. doi:10.1165/rcmb.2017-0200TR

5. Cao Y, Chen M, Dong D, Xie S, Liu M. Environmental pollutants damage airway epithelial cell cilia: Implications for the prevention of obstructive lung diseases. Thorac Cancer. 2020;11(3):505-510. doi:10.1111/1759-7714.13323

6. Maestrelli P, Saetta M, Mapp CE, Fabbri LM. Remodeling in response to infection and injury. Airway inflammation and hypersecretion of mucus in smoking subjects with chronic obstructive pulmonary disease. Am J Respir Crit Care Med. 2001;164(10 Pt 2):S76-S80. doi:10.1164/ajrccm.164.supplement_2.2106067

7. Lin VY, Kaza N, Birket SE, et al. Excess mucus viscosity and airway dehydration impact COPD airway clearance. Eur Respir J. 2020;55(1). doi:10.1183/13993003.00419-2019

8. Miyashita L, Suri R, Dearing E, et al. E-cigarette vapour enhances pneumococcal adherence to airway epithelial cells. Eur Respir J. 2018;51(2). doi:10.1183/13993003.01592-2017

9. Deeb RS, Walters MS, Strulovici-Barel Y, Chen Q, Gross SS, Crystal RG. Smoking-Associated Disordering of the Airway Basal Stem/Progenitor Cell Metabotype. Am J Respir Cell Mol Biol. 2016;54(2):231-240. doi:10.1165/rcmb.2015-00550C

10. Heijink IH, Brandenburg SM, Postma DS, van Oosterhout AJ. Cigarette smoke impairs airway epithelial barrier function and cell-cell contact recovery. Eur Respir J.
2012;39(2):419-428. doi:10.1183/09031936.00193810

11. Dicpinigaitis PV. Cough reflex sensitivity in cigarette smokers. Chest. 2003;123(3):685-688. doi:10.1378/chest.123.3.685

12. Dicpinigaitis PV. Effect of tobacco and electronic cigarette use on cough reflex sensitivity. Pulm Pharmacol Ther. 2017;47:45-48. doi:10.1016/j.pupt.2017.01.013

13. Sitkauskiene B, Dicpinigaitis PV. Effect of smoking on cough reflex sensitivity in humans. Lung. 2010;188(Suppl 1):S29-S32. doi:10.1007/s00408-009-9188-9

14. Dicpinigaitis PV, Sitkauskiene B, Stravinskaite K, Appel DW, Negassa A, Sakalauskas R. Effect of smoking cessation on cough reflex sensitivity. Eur Respir J. 2006;28(4):786790. doi:10.1183/09031936.06.00007806

15. Wistuba II, Gazdar AF. Lung cancer preneoplasia. Annu Rev Pathol Mech Dis. 2006;1:331-348. doi:10.1146/annurev.pathol.1.110304.100103

16. Tzortzaki E, Dimakou K, Neofytou E, et al. Oxidative DNA damage and somatic mutations: a link to the molecular pathogenesis of chronic inflammatory airway diseases. Chest. 2012;141(5):1243-1250. doi:10.1378/chest.11-1653

17. Siafakas N, Tzortzaki E, Sourvinos G, et al. Microsatellite DNA instability in COPD. Chest. 1999;116(1):47-51. doi:10.1378/chest.116.1.47

18. Samara K, Zervou M, Siafakas N, Tzortzaki E. Microsatellite DNA instability in benign lung diseases. Respir Med. 2006;100(2):202-211. doi:10.1016/j.rmed.2005.05.015

19. Capkova L, Kalinova M, Krskova L, et al. Loss of heterozygosity and human telomerase reverse transcriptase (hTERT) expression in bronchial mucosa of heavy smokers. Cancer. 2007;109(11):2299-2307. doi:10.1002/cncr.22683

20. Mao L, Lee J, Kurie J, et al. Clonal genetic alterations in the lungs of current and former smokers. J Natl Cancer Inst. 1997;89(12):857-862. doi:10.1093/jnci/89.12.857

21. Racanelli AC, Kikkers SA, Choi AMK, Cloonan SM. Autophagy and inflammation in chronic respiratory disease. Autophagy. 2018;14(2):221-232. doi:10.1080/15548627.2017.1389823

22. Yao RQ, Ren C, Xia ZF, Yao YM. Organelle-specific autophagy in inflammatory diseases: a potential therapeutic target underlying the quality control of multiple organelles. Autophagy. 2020:117. doi:10.1080/15548627.2020.1725377

23. Ahmad T, Sundar I, Lerner C, et al. Impaired mitophagy leads to cigarette smoke stress-induced cellular senescence: implications for chronic obstructive pulmonary disease. FASEB J. 2015;29(7):2912-2929. doi:10.1096/fj.14-268276

24. Zhang M, Shi R, Zhang Y, et al. Nix/BNIP3Ldependent mitophagy accounts for airway epithelial cell injury induced by cigarette smoke. J Cell Physiol. 2019;234(8):14210-14220. doi:10.1002/jcp.28117

25. Araya J, Tsubouchi K, Sato N, et al. PRKN-regulated mitophagy and cellular senescence during COPD pathogenesis. Autophagy. 2019;15(3):510-526. 
doi:10.1080/15548627.2018.1532259

26. Wiegman C, Michaeloudes C, Haji G, et al. Oxidative stress-induced mitochondrial dysfunction drives inflammation and airway smooth muscle remodeling in patients with chronic obstructive pulmonary disease. J Allergy Clin Immunol. 2015;136(3):769-780. doi:10.1016/j.jaci.2015.01.046

27. Aravamudan B, Kiel A, Freeman M, et al. Cigarette smoke-induced mitochondrial fragmentation and dysfunction in human airway smooth muscle. Am J Physiol Lung Cell Mol Physiol. 2014;306(9):L840-L854. doi:10.1152/ajplung.00155.2013

28. Lerner C, Sundar I, Rahman I. Mitochondrial redox system, dynamics, and dysfunction in lung inflammaging and COPD. Int J Biochem Cell Biol. 2016;81:294-306. doi:10.1016/j.biocel.2016.07.026

29. Zhang L, Wang W, Zhu B, Wang X. Epithelial Mitochondrial Dysfunction in Lung Disease. Adv Exp Med Biol. 2017;1038:201-217. doi:10.1007/978-981-10-6674-0_14

30. He Z, Chen Y, Hou C, He W, Chen P. Cigarette Smoke Extract Changes Expression of Endothelial Nitric Oxide Synthase (eNOS) and p16(INK4a) and is Related to Endothelial Progenitor Cell Dysfunction. Med Sci Monit. 2017;23:3224-3231. doi:10.12659/msm.902746

31. Ricciardolo F, Sterk P, Gaston B, Folkerts G. Nitric oxide in health and disease of the respiratory system. Physiol Rev. 2004;84(3):731-765. doi:10.1152/physrev.00034.2003

32. Ricciardolo F. Multiple roles of nitric oxide in the airways. Thorax. 2003;58(2):175-182. doi:10.1136/thorax.58.2.175

33. Bergström J. Tobacco smoking and chronic destructive periodontal disease. Odontology. 2004;92(1):1-8. doi:10.1007/s10266-004-0043-4

34. Yan C, Avadhani N, Iqbal J. The effects of smoke carcinogens on bone. Curr Osteoporos Rep. 2011;9(4):202-209. doi:10.1007/s11914-011-0068-x

35. Yoon V, Maalouf N, Sakhaee K. The effects of smoking on bone metabolism. Osteoporos Int. 2012;23(8):20812092. doi:10.1007/s00198-012-1940-y

36. Kubota M, Yanagita M, Mori K, et al. The Effects of Cigarette Smoke Condensate and Nicotine on Periodontal Tissue in a Periodontitis Model Mouse. PloS One. 2016;11(5):e0155594. doi:10.1371/journal.pone.0155594

37. Camelo-Castillo AJ, Mira A, Pico A, et al. Subgingival microbiota in health compared to periodontitis and the influence of smoking. Front Microbiol. 2015;6:119. doi:10.3389/fmicb.2015.00119

38. Cho YD, Kim PJ, Kim HG, et al. Transcriptomics and methylomics in chronic periodontitis with tobacco use: a pilot study. Clin Epigenetics. 2017;9:81. doi:10.1186/s13148-017-0381-z

39. Li LF, Chan RLY, Lu L, et al. Cigarette smoking and gastrointestinal diseases: the causal relationship and underlying molecular mechanisms (review). Int J Mol Med. 2014;34(2):372-380. doi:10.3892/ijmm.2014.1786
40. Kim K, Chang Y, Ahn J, et al. Smoking and Urinary Cotinine Levels Are Predictors of Increased Risk for Gastric Intestinal Metaplasia. Cancer Res. 2019;79(3):676684. doi:10.1158/0008-5472.can-18-2268

41. Tan MC, Mallepally N, Liu Y, El-Serag HB, Thrift AP. Demographic and Lifestyle Risk Factors for Gastric Intestinal Metaplasia Among US Veterans. Am J Gastroenterol. 2020;115(3):381-387. doi:10.14309/ajg.0000000000000498

42. Kneller RW, You WC, Chang YS, et al. Cigarette smoking and other risk factors for progression of precancerous stomach lesions. J Natl Cancer Inst. 1992;84(16):12611266. doi:10.1093/jnci/84.16.1261

43. Yu H. The effect of smoking and drinking on stomach infection of Helicobacter pylori. Journal of Local Surgery. 2011;20(01):84.

44. Lee J, Taneja V, Vassallo R. Cigarette smoking and inflammation: cellular and molecular mechanisms. J Dent Res. 2012;91(2):142-149. doi:10.1177/0022034511421200

45. Stampfli MR, Anderson GP. How cigarette smoke skews immune responses to promote infection, lung disease and cancer. Nat Rev Immunol. 2009;9(5):377-384. doi:10.1038/nri2530

46. Garmendia J, Morey P, Bengoechea JA. Impact of cigarette smoke exposure on host-bacterial pathogen interactions. Eur Respir J. 2012;39(2):467-477. doi:10.1183/09031936.00061911

47. Qiu F, Liang CL, Liu H, et al. Impacts of cigarette smoking on immune responsiveness: Up and down or upside down? Oncotarget. 2017;8(1):268-284. doi:10.18632/oncotarget.13613

48. O'Leary SM, Coleman MM, Chew WM, et al. Cigarette smoking impairs human pulmonary immunity to Mycobacterium tuberculosis. Am J Respir Crit Care Med. 2014;190(12):14301436. doi:10.1164/rccm.201407-13850C

49. Ni I, Ji C, Vij N. Second-hand cigarette smoke impairs bacterial phagocytosis in macrophages by modulating CFTR dependent lipid-rafts. PloS One. 2015;10(3):e0121200. doi:10.1371/journal.pone.0121200

50. Hodge S, Hodge G, Ahern J, Jersmann H, Holmes M, Reynolds P. Smoking alters alveolar macrophage recognition and phagocytic ability: implications in chronic obstructive pulmonary disease. Am J Respir Cell Mol Biol. 2007;37(6):748-755. doi:10.1165/rcmb.2007-00250C

51. Berenson CS, Garlipp MA, Grove LJ, Maloney J, Sethi S. Impaired phagocytosis of nontypeable Haemophilus influenzae by human alveolar macrophages in chronic obstructive pulmonary disease. J Infect Dis. 2006;194(10):1375-1384. doi:10.1086/508428

52. Givi M, Folkerts G, Wagenaar G, Redegeld F, Mortaz E. Cigarette smoke differentially modulates dendritic cell maturation and function in time. Respir Res. 2015;16:131. doi:10.1186/s12931-015-0291-6

53. Mortaz E, Lazar Z, Koenderman L, Kraneveld A, Nijkamp F, Folkerts G. Cigarette smoke attenuates 
the production of cytokines by human plasmacytoid dendritic cells and enhances the release of IL-8 in response to TLR-9 stimulation. Respir Res. 2009;10:47. d oi:10.1186/1465-9921-10-47

54. Robbins C, Franco F, Mouded M, Cernadas M, Shapiro S. Cigarette smoke exposure impairs dendritic cell maturation and $\mathrm{T}$ cell proliferation in thoracic lymph nodes of mice. J Immunol. 2008;180(10):6623-6628. doi:10.4049/jimmunol.180.10.6623

55. Tollerud D, Clark J, Brown L, et al. Association of cigarette smoking with decreased numbers of circulating natural killer cells. Am Rev Respir Dis. 1989;139(1):194-198. doi:10.1164/ajrccm/139.1.194

56. Mian M, Lauzon N, Stämpfli M, Mossman K, Ashkar A. Impairment of human NK cell cytotoxic activity and cytokine release by cigarette smoke. J Leukoc Biol. 2008;83(3):774-784. doi:10.1189/jlb.0707481

57. Corriden R, Moshensky A, Bojanowski CM, et al. E-cigarette use increases susceptibility to bacterial infection by impairment of human neutrophil chemotaxis, phagocytosis, and NET formation. Am J Physiol Cell Physiol. 2020;318(1):C205-C214. doi:10.1152/ajpcell.00045.2019

58. Moore PJ, Sesma J, Alexis NE, Tarran R. Tobacco exposure inhibits SPLUNC1-dependent antimicrobial activity. Respir Res. 2019;20(1):94. doi:10.1186/s12931-019-1066-2

59. Duffney PF, McCarthy CE, Nogales A, et al. Cigarette smoke dampens antiviral signaling in small airway epithelial cells by disrupting TLR3 cleavage. Am J Physiol Lung Cell Mol Physiol. 2018;314(3):L505-L513. doi:10.1152/ajplung.00406.2017

60. Liu G, Arimilli S, Savage E, Prasad GL. Cigarette smoke preparations, not moist snuff, impair expression of genes involved in immune signaling and cytolytic functions. Sci Rep. 2019;9(1):13390. doi:10.1038/s41598-019-48822-w

61. Warny M, Helby J, Nordestgaard BG, Birgens H, Bojesen SE. Lymphopenia and risk of infection and infection-related death in 98,344 individuals from a prospective Danish population-based study. PLoS Med. 2018;15(11):e1002685. doi:10.1371/journal.pmed.1002685

62. Bhat TA, Kalathil SG, Bogner PN, et al. Secondhand Smoke Induces Inflammation and Impairs Immunity to Respiratory Infections. J Immunol. 2018;200(8):29272940. doi:10.4049/jimmunol.1701417

63. Patin E, Hasan M, Bergstedt J, et al. Natural variation in the parameters of innate immune cells is preferentially driven by genetic factors. Nat Immunol. 2018;19(3):302314. doi:10.1038/s41590-018-0049-7

64. Gonzalez-Quintela A, Alende R, Gude F, et al. Serum levels of immunoglobulins ( $\mathrm{IgG}, \operatorname{IgA}, \operatorname{IgM}$ ) in a general adult population and their relationship with alcohol consumption, smoking and common metabolic abnormalities. Clin Exp Immunol. 2008;151(1):42-50. doi:10.1111/j.1365-2249.2007.03545.x

65. Tarbiah N, Todd I, Tighe P, Fairclough L. Cigarette smoking differentially affects immunoglobulin class levels in serum and saliva: An investigation and review. Basic Clin Pharmacol Toxicol. 2019;125(5):474-483. doi:10.1111/bcpt.13278

66. Giuca M, Pasini M, Tecco S, Giuca G, Marzo G. Levels of salivary immunoglobulins and periodontal evaluation in smoking patients. BMC immunol. 2014;15:5. doi:10.1186/1471-2172-15-5

67. Hersey P, Prendergast D, Edwards A. Effects of cigarette smoking on the immune system. Follow-up studies in normal subjects after cessation of smoking. Med J Aust. 1983;2(9):425429. doi:10.5694/j.1326-5377.1983.tb122565.x

68. Arimilli S, Makena P, Liu G, Prasad GL. Distinct gene expression changes in human peripheral blood mononuclear cells treated with different tobacco product preparations. Toxicol In Vitro. 2019;57:117-125. doi:10.1016/j.tiv.2019.02.012

69. Baik I, Curhan GC, Rimm EB, Bendich A, Willett WC, Fawzi WW. A prospective study of age and lifestyle factors in relation to community-acquired pneumonia in US men and women. Arch Intern Med. 2000;160(20):3082-3088. doi:10.1001/archinte.160.20.3082

70. Almirall J, Serra-Prat M, Bolibar I, Balasso V. Risk Factors for Community-Acquired Pneumonia in Adults: A Systematic Review of Observational Studies. Respiration. 2017;94(3):299-311. doi:10.1159/000479089

71. Ruan T, Xu X. [Analysis of risk factors related to community-acquired pneumonia in the elderly]. Chinese Journal of Geriatrics. 2015;34(7):720-722.

72. Bai R, Xu B, Sun T, Zhang T, He L. [A case-control study on risk factors for community-acquired pneumonia in the elderly in Shanghai]. Health Research. 2007;36(5):587590. PMID:18095574

73. Nuorti JP, Butler JC, Farley MM, et al. Cigarette smoking and invasive pneumococcal disease. Active Bacterial Core Surveillance Team. N Engl J Med. 2000;342(10):681689. doi:10.1056/nejm200003093421002

74. Almirall J, Bolibar I, Serra-Prat M, et al. New evidence of risk factors for community-acquired pneumonia: a population-based study. Eur Respir J. 2008;31(6):12741284. doi:10.1183/09031936.00095807

75. Almirall J, Gonzalez CA, Balanzo X, Bolibar I. Proportion of community-acquired pneumonia cases attributable to tobacco smoking. Chest. 1999;116(2):375-379. doi:10.1378/chest.116.2.375

76. Cohen S, Tyrrell DA, Russell MA, Jarvis MJ, Smith AP. Smoking, alcohol consumption, and susceptibility to the common cold. Am J Public Health. 1993;83(9):12771283. doi:10.2105/ajph.83.9.1277

77. Blake GH, Abell TD, Stanley WG. Cigarette smoking and upper respiratory infection among recruits in basic combat training. Ann Intern Med. 1988;109(3):198-202. doi:10.7326/0003-4819-109-3-198

78. An LC, Berg CJ, Klatt CM, et al. Symptoms of cough and shortness of breath among occasional young adult 
smokers. Nicotine Tob Res. 2009;11(2):126-133. doi:10.1093/ntr/ntp015

79. Aronson MD, Weiss ST, Ben RL, Komaroff AL. Association between cigarette smoking and acute respiratory tract illness in young adults. JAMA. 1982;248(2):181-183. doi:10.1001/jama.248.2.181

80. Zhou G, Liu H, He M, et al. Smoking, leisure-time exercise and frequency of self-reported common cold among the general population in northeastern China: a crosssectional study. BMC Public Health. 2018;18(1):294. doi:10.1186/s12889-018-5203-5

81. Guan Y, Zhao M, Zhao G. [Analysis of risk factors for children with repeated upper respiratory tract infections]. Chinese Journal of Hospital Infectology. 2014;24.

82. Godoy P, Castilla J, Soldevila N, et al. Smoking may increase the risk of influenza hospitalization and reduce influenza vaccine effectiveness in the elderly. Eur J Public Health. 2018;28(1):150-155. doi:10.1093/eurpub/ckx130

83. Park JK, Lee S, Lee JE, et al. The Association between Smoking Status and Influenza Vaccination Coverage Rate in Korean Adults: Analysis of the 2010-2012 Korea National Health and Nutrition Examination Survey. Korean J Fam Med. 2018;39(2):90-95. doi:10.4082/kjfm.2018.39.2.90

84. Lee JS, Ki SY, Hwang IS, et al. Effect of Smoking on Influenza Illness and Vaccine-induced Immune Response in Mice. Infect Chemother. 2010;42(6):391. doi:10.3947/ ic.2010.42.6.391

85. World Health Organization. Coronavirus disease (COVID-19) outbreak situation. https://www.who.int/ emergencies/diseases/novel-coronavirus-2019. Accessed December 24, 2019.

86. Leung J, Sin D. Smoking, ACE-2, and COVID-19: Ongoing Controversies. Eur Respir J. 2020. doi:10.1183/13993003.01759-2020

87. Brake SJ, Barnsley K, Lu W, McAlinden KD, Eapen MS, Sohal SS. Smoking Upregulates Angiotensin-Converting Enzyme-2 Receptor: A Potential Adhesion Site for Novel Coronavirus SARS-CoV-2 (Covid-19). J Clin Med. 2020;9(3). doi:10.3390/jcm9030841

88. Xie M, Chen Q. Insight into 2019 novel coronavirus - an updated interim review and lessons from SARS-CoV and MERS-CoV. Int J Infect Dis. 2020. doi:10.1016/j.ijid.2020.03.071

89. Zhang H, Rostami M, Leopold P, et al. Expression of the SARS-CoV-2 ACE2 Receptor in the Human Airway Epithelium. Am J Respir Crit Care Med. 2020. doi:10.1164/rccm.202003-05410C

90. Chakladar J, Shende N, Li W, Rajasekaran M, Chang E, Ongkeko W. Smoking-Mediated Upregulation of the Androgen Pathway Leads to Increased SARSCoV-2 Susceptibility. Int J Mol Sci. 2020;21(10). doi:10.3390/ijms21103627

91. Yan R, Zhang Y, Li Y, Xia L, Guo Y, Zhou Q. Structural basis for the recognition of SARS-CoV-2 by full-length human ACE2. Science. 2020;367(6485):1444-1448. doi:10.1126/science.abb2762

92. Li G, He X, Zhang L, et al. Assessing ACE2 expression patterns in lung tissues in the pathogenesis of COVID-19. J Autoimmun. 2020:102463. doi:10.1016/j.jaut.2020.102463

93. He L, Ding Y, Zhang Q, et al. Expression of elevated levels of pro-inflammatory cytokines in SARS-CoVinfected ACE2+ cells in SARS patients: relation to the acute lung injury and pathogenesis of SARS. J Pathol. 2006;210(3):288-297. doi:10.1002/path.2067

94. Hamer M, Kivimäki M, Gale C, Batty G. Lifestyle risk factors, inflammatory mechanisms, and COVID-19 hospitalization: A community-based cohort study of 387,109 adults in UK. Brain Behav Immun. 2020. doi:10.1016/j.bbi.2020.05.059

95. Vardavas CI, Nikitara K. COVID-19 and smoking: A systematic review of the evidence. Tob Induc Dis. 2020;18(March). doi:10.18332/tid/119324

96. Liu W, Tao ZW, Wang L, et al. Analysis of factors associated with disease outcomes in hospitalized patients with 2019 novel coronavirus disease. Chin Med J (Engl). 2020;133(9). doi:10.1097/cm9.0000000000000775

97. Guan WJ, Ni ZY, Hu Y, et al. Clinical Characteristics of Coronavirus Disease 2019 in China. N Engl J Med. 2020;382(18):1708-1720. doi:10.1056/NEJMoa2002032

98. Lew TWK, MMed, Kwek TK, Tai D, et al. Acute respiratory distress syndrome in critically ill patients with severe acute respiratory syndrome. JAMA. 2003;290(3):374380. doi:10.1001/jama.290.3.374

99. Lee N, Hui D, Wu A, et al. A major outbreak of severe acute respiratory syndrome in Hong Kong. N Engl J Med. 2003;348(20):1986-1994. doi:10.1056/NEJMoa030685

100.Alraddadi B, Watson J, Almarashi A, et al. Risk Factors for Primary Middle East Respiratory Syndrome Coronavirus Illness in Humans, Saudi Arabia, 2014. Emerg Infect Dis. 2016;22(1):49-55. doi:10.3201/eid2201.151340

101.Nam HS, Park J, Ki M, Yeon MY, Kim J, Kim S. High fatality rates and associated factors in two hospital outbreaks of MERS in Daejeon, the Republic of Korea. Int J Infect Dis. 2017;58:37-42. doi:10.1016/j.ijid.2017.02.008

102.Cai H. Sex difference and smoking predisposition in patients with COVID-19. Lancet Respir Med. 2020;8(4):e20. doi:10.1016/s2213-2600(20)30117-x

103.Farsalinos K, Angelopoulou A, Alexandris N, Poulas K. COVID-19 and the nicotinic cholinergic system. Eur Respir J. 2020. doi:10.1183/13993003.01589-2020

104.de Lusignan S, Dorward J, Correa A, et al. Risk factors for SARS-CoV-2 among patients in the Oxford Royal College of General Practitioners Research and Surveillance Centre primary care network: a cross-sectional study. Lancet Infect Dis. 2020. doi:10.1016/s1473-3099(20)30371-6

105.Lippi G, Henry BM. Active smoking is not associated with severity of coronavirus disease 2019 (COVID-19). Eur J Intern Med. 2020. doi:10.1016/j.ejim.2020.03.014 
106.Guo FR. Active smoking is associated with severity of coronavirus disease 2019 (COVID-19): An update of a meta-analysis. Tob Induc Dis. 2020;18(May). doi:10.18332/tid/121915

107.Patanavanich R, Glantz S. Smoking is Associated with COVID-19 Progression: A Meta-Analysis. Nicotine Tob Res. 2020. doi:10.1093/ntr/ntaa082

108. Rossato M, Russo L, Mazzocut S, Di Vincenzo A, Fioretto P, Vettor R. Current Smoking is Not Associated with COVID-19. Eur Respir J. 2020. doi:10.1183/13993003.01290-2020

109. World Health Organization. Smoking and COVID-19. https://www.who.int/news-room/commentaries/detail/ smoking-and-covid-19. Accessed December 24, 2019.

110.Kark JD, Lebiush M. Smoking and epidemic influenzalike illness in female military recruits: a brief survey. Am J Public Health. 1981;71(5):530-532. doi:10.2105/ajph.71.5.530

111.Kark JD, Lebiush M, Rannon L. Cigarette smoking as a risk factor for epidemic $\mathrm{A}(\mathrm{H} 1 \mathrm{~N} 1)$ influenza in young men. N Engl J Med. 1982;307(17):1042-1046. doi:10.1056/nejm198210213071702

112.Cortuk M, Acat M, Yazici O, et al. Retrospective review of epidemic viral pneumonia cases in Turkey: A multicenter study. Exp Ther Med. 2017;13(4):14311437. doi:10.3892/etm.2017.4153

113.Xu L, Chen B, Wang F, et al. [A Higher Rate of Pulmonary Fungal Infection in Chronic Obstructive Pulmonary Disease Patients with Influenza in a Large Tertiary Hospital]. Respiration. 2019;98:391-400. doi:10.1159/000501410

114.Flory JH, Joffe M, Fishman NO, Edelstein PH, Metlay JP. Socioeconomic risk factors for bacteraemic pneumococcal pneumonia in adults. Epidemiol Infect. 2009;137(5):717726. doi:10.1017/s0950268808001489

115.Jacups SP, Cheng A. The epidemiology of community acquired bacteremic pneumonia, due to Streptococcus pneumoniae, in the Top End of the Northern Territory, Australia--over 22 years. Vaccine. 2011;29(33):53865392. doi:10.1016/j.vaccine.2011.05.082

116.Straus WL, Plouffe JF, File TM Jr, et al. Risk factors for domestic acquisition of legionnaires disease. Ohio legionnaires Disease Group. Arch Intern Med. 1996;156(15):1685-1692. PMID:8694667

117.Doebbeling BN, Wenzel RP. The epidemiology of Legionella pneumophila infections. Semin Respir Infect. 1987;2(4):206-221. PMID:3328890

118. Caira M, Candoni A, Verga L, et al. Pre-chemotherapy risk factors for invasive fungal diseases: prospective analysis of 1,192 patients with newly diagnosed acute myeloid leukemia (SEIFEM 2010-a multicenter study). Haematologica. 2015;100(2):284-292. doi:10.3324/haematol.2014.113399

119.Rosenstein NE, Emery KW, Werner SB, et al. Risk factors for severe pulmonary and disseminated coccidioidomycosis: Kern County, California, 1995-1996. Clin Infect Dis. 2001;32(5):708-715. doi:10.1086/319203

120. Cheemarla NR, Uche IK, McBride K, Naidu S, Guerrero-

Plata A. In utero tobacco smoke exposure alters lung inflammation, viral clearance, and CD8+ T-cell responses in neonatal mice infected with respiratory syncytial virus. Am J Physiol Lung Cell Mol Physiol. 2019;317(2):L212-L221. doi:10.1152/ajplung.00338.2018

121. World Health Organization. Global Tuberculosis Report 2017. https://www.who.int/tb/publications/ global_report/gtbr2017_main_text.pdf?ua=1. Accessed December 24, 2019.

122. Wei J, Peng L, Chen H. [Meta analysis of smoking and the incidence of tuberculosis in Chinese population]. Chongqing Medicine. 2017;46(16):2224-2232. doi:10.3969/j.issn.1671-8348.2017.16.020.

123. Yang B, Qi F. [Meta analysis of the relationship between smoking and tuberculosis]. Chinese Journal of Behavioral Medicine and Brain Science. 2010;19(11):1025-1028. doi:10.3760/cma.j.issn.1674-6554.2010.11.024

124.Bates MN, Khalakdina A, Pai M, Chang L, Lessa F, Smith KR. Risk of tuberculosis from exposure to tobacco smoke: a systematic review and meta-analysis. Arch Intern Med. 2007;167(4):335-342. doi:10.1001/archinte.167.4.335

125.Lin HH, Ezzati M, Chang HY, Murray M. Association between tobacco smoking and active tuberculosis in Taiwan: prospective cohort study. Am J Respir Crit Care Med. 2009;180(5):475-480. doi:10.1164/rccm.200904-05490C

126.Ozturk AB, Kilicaslan Z, Issever H. Effect of smoking and indoor air pollution on the risk of tuberculosis: smoking, indoor air pollution and tuberculosis. Tuberkuloz ve Toraks. 2014;62(1):1-6. doi:10.5578/tt.7013

127.Horne DJ, Campo M, Ortiz JR, et al. Association between smoking and latent tuberculosis in the U.S. population: an analysis of the National Health and Nutrition Examination Survey. PloS One. 2012;7(11):e49050. doi:10.1371/journal.pone.0049050

128.Bronner ML, Martinson N, Moloney RM, et al. Tobacco Smoking and Tuberculosis among Men Living with HIV in Johannesburg, South Africa: A Case-Control Study. PloS One. 2016;11(11):e0167133. doi:10.1371/journal. pone. 0167133

129.Leung CG, Li T, Lam TH, et al. Smoking and tuberculosis among the elderly in Hong Kong. Am J Respir Crit Care Med. 2004;170(9):1027-1033. doi:10.1164/rccm.200404-5120C

130.Abal AT, Jayakrishnan B, Parwer S, El Shamy A, Abahussain E, Sharma PN. Effect of cigarette smoking on sputum smear conversion in adults with active pulmonary tuberculosis. Respir Med. 2005;99(4):415420. doi:10.1016/j.rmed.2004.08.016

131.Tan S, Liang M, Lin Z, Guan Y, Li Y. The effect of smoking on tuberculosis. Journal of Practical Medicine. 2005(21):2368-2370.

132. Chuang HC, Su CL, Liu HC, et al. Cigarette smoke is a risk factor for severity and treatment outcome in patients 
with culture-positive tuberculosis. Ther Clin Risk Manag. 2015;11:1539-1544. doi:10.2147/tcrm.s87218

133.Xiong S. [The effect of smoking on the efficacy of DOTS in tuberculosis patients]. Practical Clinical Medicine. 2016;17(11):96-98.

134.Lin Y, Wang LX, Qiu LX, et al. A smoking cessation intervention among tuberculosis patients in rural China. Public Health Action. 2015;5(3):183-187. doi:10.5588/pha.15.0025

135.Gajalakshmi V, Peto R, Kanaka TS, Jha P. Smoking and mortality from tuberculosis and other diseases in India: retrospective study of 43000 adult male deaths and 35000 controls. Lancet. 2003;362(9383):507-515. doi:10.1016/s0140-6736(03)14109-8

136.Zhang X, Chen H, Yang G. [Analysis of Helicobacter pylori infection in healthy people]. Chinese Journal of Social Medicine. 2017;34(3):313-315. doi:10.3969/j.issn.1673-5625.2017.03.032

137. Ozaydin N, Turkyilmaz SA, Cali S. Prevalence and risk factors of Helicobacter pylori in Turkey: a nationallyrepresentative, cross-sectional, screening with the (1)(3) C-Urea breath test. BMC Public Health. 2013;13:1215. doi:10.1186/1471-2458-13-1215

138. Chen L, Jia X, Wang S. [Analysis of current status and risk factors of Helicobacter pylori infection in medical examination population in Miyun District, Beijing]. Clinical Medicine of China. 2017;33(10):891-894. doi:10.3760/cma.j.issn.1008-6315.2017.10.007

139.Itskoviz D, Boltin D, Leibovitzh H, et al. Smoking increases the likelihood of Helicobacter pylori treatment failure. Dig Liver Dis. 2017;49(7):764-768. doi:10.1016/j.dld.2017.03.010

140.Rogers MA, Greene MT, Saint S, et al. Higher rates of Clostridium difficile infection among smokers. PloS One. 2012;7(7):e42091. doi:10.1371/journal.pone.0042091

141.Barker AK, Van Galen A, Sethi AK, Shirley D, Safdar N. Tobacco use as a screener for Clostridium difficile infection outcomes. J Hosp Infect. 2018;98(1):36-39. doi:10.1016/j.jhin.2017.06.026

142.Ruiter-Ligeti J, Vincent S, Czuzoj-Shulman N, Abenhaim HA. Risk Factors, Incidence, and Morbidity Associated With Obstetric Clostridium difficile Infection. Obstet Gynecol. 2018;131(2):387-391. doi:10.1097/aog.0000000000002422

143.Garg SK, Obaitan I, Sarvepalli S, Anugwom CM, Pardi DS, Khanna S. Clostridium difficile Infection in the Emergency Department. J Clin Gastroenterol. 2019. doi:10.1097/mcg.0000000000001252

144.Zheng LH, Zhang AZ, Shi YY, et al. Impact of Smoking on Anal Abscess and Anal Fistula Diseases. Chin Med J. 2018;131(9):1034-1037. doi:10.4103/0366-6999.230738

145.Devaraj B, Khabassi S, Cosman BC. Recent smoking is a risk factor for anal abscess and fistula. Dis Colon Rectum. 2011;54(6):681-685. doi:10.1007/DCR.0b013e31820e7c7a 146. Wang D, Yang G, Qiu J, et al. Risk factors for anal fistula: a case-control study. Tech Coloproctol. 2014;18(7):635639. doi:10.1007/s10151-013-1111-y

147.Eldridge RC, Pawlita M, Wilson L, et al. Smoking and subsequent human papillomavirus infection: a mediation analysis. Ann Epidemiol. 2017;27(11):724-730.e1. doi:10.1016/j.annepidem.2017.10.004

148.Feng RM, Hu SY, Zhao FH, et al. Role of active and passive smoking in high-risk human papillomavirus infection and cervical intraepithelial neoplasia grade 2 or worse. J Gynecol Oncol. 2017;28(5):e47. doi:10.3802/jgo.2017.28.e47

149.Liu Z, Nyitray AG, Hwang LY, et al. Human Papillomavirus Prevalence Among 88 Male Virgins Residing in Brazil, Mexico, and the United States. J Infect Dis. 2016;214(8):1188-1191. doi:10.1093/infdis/jiw353

150.Chandrupatla SG, Khalid I, Tavares M. Oral HPV prevalence and HPV vaccination among special needs population in the US. Papillomavirus Res. 2019;8:100182. doi:10.1016/j.pvr.2019.100182

151.Grama DF, da Silva Casarotti L, de Andrade Morato MG, et al. Prevalence of Trichomonas vaginalis and risk factors in women treated at public health units in Brazil: a transversal study. Trans R Soc Trop Med Hyg. 2013;107(9):584-591. doi:10.1093/trstmh/trt063

152.Lockhart A, Senkomago V, Ting J, et al. Prevalence and Risk Factors of Trichomonas vaginalis Among Female Sexual Workers in Nairobi, Kenya. Sex Transm Dis. 2019;46(7):458-464. doi:10.1097/olq.0000000000001002

153.Balkus JE, Manhart LE, Jensen JS, et al. Mycoplasma genitalium Infection in Kenyan and US Women. Sex Transm Dis. 2018;45(8):514-521. doi:10.1097/olq.0000000000000799

154.Aghaizu A, Reid F, Kerry S, et al. Frequency and risk factors for incident and redetected Chlamydia trachomatis infection in sexually active, young, multi-ethnic women: a community based cohort study. Sex Transm Infect. 2014;90(7):524-528. doi:10.1136/sextrans-2014-051607

155.Barnes R, Bowen AC, Walker R, et al. Perinatal risk factors associated with skin infection hospitalisation in Western Australian Aboriginal and Non-Aboriginal children. Paediatr Perinat Epidemiol. 2019;33(5):374383. doi:10.1111/ppe.12573

156.Jensen RG, Koch A, Homoe P, Bjerregaard P. Tobacco smoke increases the risk of otitis media among Greenlandic Inuit children while exposure to organochlorines remain insignificant. Environ Int. 2013;54:112-118. doi:10.1016/j.envint.2013.01.015

157.Stathis SL, O'Callaghan DM, Williams GM, Najman JM, Andersen MJ, Bor W. Maternal cigarette smoking during pregnancy is an independent predictor for symptoms of middle ear disease at five years' postdelivery. Pediatrics. 1999;104(2):e16. doi:10.1542/peds.104.2.e16

158. Ojima M, Hanioka T, Tanaka K, Inoshita E, Aoyama H. Relationship between smoking status and periodontal conditions: findings from national databases in 
Japan. J Periodontal Res. 2006;41(6):573-579. doi:10.1111/j.1600-0765.2006.00915.x

159.Tomar SL, Asma S. Smoking-attributable periodontitis in the United States: findings from NHANES III. National Health and Nutrition Examination Survey. J Periodontol. 2000;71(5):743-751. doi:10.1902/jop.2000.71.5.743

160.Zhang Junjian. Correlation analysis of risk factors for severe periodontitis in the elderly. Journal of Practical Stomatology. 2015;31(06):841-843.

161.Kinane DF, Radvar M. The effect of smoking on mechanical and antimicrobial periodontal therapy. J Periodontol. 1997;68(5):467-472. doi:10.1902/jop.1997.68.5.467

162.Zhao X, Liu J, Wang H, Sun S, Pan YP. [Study on the epidemiological factors of periodontitis in adults]. Stomatology Research. 2006;(06):625 -628.

163.Huttunen R, Laine J, Lumio J, Vuento R, Syrjanen J. Obesity and smoking are factors associated with poor prognosis in patients with bacteraemia. BMC Infect Dis. 2007;7:13. doi:10.1186/1471-2334-7-13

164.Cobo F, Cabezas-Fernandez MT, Cabeza-Barrera MI. Streptococcus pneumoniae bacteremia: clinical and microbiological epidemiology in a health area of Southern Spain. Infect Dis Rep. 2012;4(2):e29. doi:10.4081/idr.2012.e29

165.Mdodo R, Frazier EL, Dube SR, et al. Cigarette smoking prevalence among adults with HIV compared with the general adult population in the United States: crosssectional surveys. Ann Intern Med. 2015;162(5):335-344. doi:10.7326/m14-0954

166.Feldman JG, Minkoff H, Schneider MF, et al. Association of cigarette smoking with HIV prognosis among women in the HAART era: a report from the women's interagency HIV study. Am J Public Health. 2006;96(6):1060-1065. doi:10.2105/ajph.2005.062745

167. Rossouw T, Anderson R, Feldman C. Impact of HIV infection and smoking on lung immunity and related disorders. Eur Respir J. 2015;46(6):1781-1795. doi:10.1183/13993003.00353-2015

168.Davies TL, Gompels M, Johnston S, Bovill B, May MT. Mind the gap: difference between Framingham heart age and real age increases with age in HIV-positive individuals-a clinical cohort study. BMJ Open. 2013;3(10):e003245. doi:10.1136/bmjopen-2013-003245

169.Crothers K, Griffith TA, McGinnis KA, et al. The impact of cigarette smoking on mortality, quality of life, and comorbid illness among HIV-positive veterans. J Gen Intern Med. 2005;20(12):1142-1145. doi:10.1111/j.1525-1497.2005.0255.x

170.Crothers K, Goulet JL, Rodriguez-Barradas MC, et al. Impact of cigarette smoking on mortality in HIV-positive and HIV-negative veterans. AIDS Educ Prev. 2009;21(3 Suppl):40-53. doi:10.1521/aeap.2009.21.3_supp.40

171.Cui Q, Carruthers S, McIvor A, Smaill F, Thabane L, Smieja M. Effect of smoking on lung function, respiratory symptoms and respiratory diseases amongst HIV- positive subjects: a cross-sectional study. AIDS Res Ther. 2010;7:6. doi:10.1186/1742-6405-7-6

172.Gordin FM, Roediger MP, Girard PM, et al. Pneumonia in HIV-infected persons: increased risk with cigarette smoking and treatment interruption. Am J Respir Crit Care Med. 2008;178(6):630-636. doi:10.1164/rccm.200804-6170C

173.Lifson AR, Neuhaus J, Arribas JR, van den BergWolf M, Labriola AM, Read TR. Smoking-related health risks among persons with HIV in the Strategies for Management of Antiretroviral Therapy clinical trial. Am J Public Health. 2010;100(10):1896-1903. doi:10.2105/ajph.2009.188664

174.Lifson AR, Lando HA. Smoking and HIV: prevalence, health risks, and cessation strategies. Curr HIV/AIDS Rep. 2012;9(3):223-230. doi:10.1007/s11904-012-0121-0

175. Wewers MD, Diaz PT, Wewers ME, Lowe MP, Nagaraja HN, Clanton TL. Cigarette smoking in HIV infection induces a suppressive inflammatory environment in the lung. Am J Respir Crit Care Med. 1998;158:1543-1549. doi:10.1164/ajrccm.158.5.9802035

176. Valiathan R, Miguez MJ, Patel B, Arheart KL, Asthana D. Tobacco smoking increases immune activation and impairs T-cell function in HIV infected patients on antiretrovirals: a cross-sectional pilot study. PloS One. 2014;9(5):e97698. doi:10.1371/journal.pone.0097698

177. Miguez-Burbano MJ, Ashkin D, Rodriguez A, et al. Increased risk of Pneumocystis carinii and community-acquired pneumonia with tobacco use in HIV disease. Int J Infect Dis. 2005;9(4):208-217. doi:10.1016/j.ijid.2004.07.010

178. Hasan SS. Timing Is Everything: Commentary on an article by Brian Forsythe, MD, et al.: "The Timing of Injections Prior to Arthroscopic Rotator Cuff Repair Impacts the Risk of Surgical Site Infection". J Bone Joint Surg Am. 2019;101(8):e33. doi:10.2106/jbjs.19.00173

179.Baier C, Adelmund S, Schwab F, et al. Incidence and risk factors of surgical site infection after total knee arthroplasty: Results of a retrospective cohort study. Am J Infect Control. 2019;47(10):1270-1272. doi:10.1016/j.ajic.2019.04.010

180. Wilson JRF, Jiang F, Badhiwala JH, et al. The Effect of Tobacco Smoking on Adverse Events Following Adult Complex Deformity Surgery: Analysis of 270 Patients from The Prospective, Multi-center Scoli-RISK-1 study. Spine. 2019;45(1). doi:10.1097/brs.0000000000003200

181.Xu H, Yu L, Li Y, Gong Z. Prolonged surgical duration, higher body mass index and current smoking increases risk of surgical site infection after intra-articular fracture of distal femur. ANZ J Surg. 2019;89(6):723-728. doi:10.1111/ans.15263

182.Peng W, Liang Y, Lu T, et al. Multivariate analysis of incision infection after posterior lumbar surgery in diabetic patients: A single-center retrospective analysis. Medicine. 2019;98(23): e 15935 . 
doi:10.1097/md.0000000000015935

183.Debbi EM, Rajaee SS, Spitzer AI, Paiement GD. Smoking and Total Hip Arthroplasty: Increased Inpatient Complications, Costs, and Length of Stay. J Arthroplasty. 2019;34(8):1736-1739. doi:10.1016/j.arth.2019.03.059

184. Matharu GS, Mouchti S, Twigg S, et al. The effect of smoking on outcomes following primary total hip and knee arthroplasty: a population-based cohort study of 117,024 patients. Acta Orthop. 2019;90(6):559-567. doi:10.1080/17453674.2019.1649510

185.Pigot GLS, Al-Tamimi M, Ronkes B, et al. Surgical Outcomes of Neoscrotal Augmentation with Testicular Prostheses in Transgender Men. J Sex Med. 2019;16(10):1664-1671. doi:10.1016/j.jsxm.2019.07.020

CONFLICTS OF INTEREST

The authors have completed and submitted the ICMJE Form for Disclosure of Potential Conflicts of Interest and none was reported.

FUNDING

There was no source of funding for this research.

PROVENANCE AND PEER REVIEW

Not commissioned; externally peer reviewed. 